The Chittagong Univ. J. B. Sci., Vol. 6(1 \&2):119-133, 2011.

\title{
MENTAL HEALTH STATUS OF PRIMARY SCHOOL CHILDREN OF CHITTAGONG TOWN
}

\author{
ARUNAVO BAIRAGI ${ }^{1 *}$, MD.SHAHINOOR RAHMAN ${ }^{1}$ AND TANZIR AHMMAD TUSHAR ${ }^{2}$ \\ ${ }^{1}$ Department of Psychology, University of Chittagong, Bangladesh \\ ${ }^{2}$ Department of Psychology, University of Rajshahi, Bangladesh
}

\begin{abstract}
A total of 197 respondents (129 parents of boys and 68 parents of girls) constituted the sample of the study. To measure mental health status, Bengali version of (Mullick, 2001) Strength and Difficulties Questionnaire (SDQ) was used for the collection of data which was originally developed by Michael Rutter and Robert Goodman. Purposive sampling procedure was used for this purpose. The results showed that about $20.3 \%$ students had pro-social problem and $19.3 \%$ students were in borderline level in pro-social behavior. Only $0.5 \%$ students had Peer problems and $15.7 \%$ students were found at borderline level of this problem. About $6.6 \%$ students had hyperactivity problem and about $5.6 \%$ students were found at borderline level of this problem. About $1.5 \%$ students had Emotional symptom problem and $0.5 \%$ students were found at borderline level. About $19.3 \%$ students had conduct problem and $23.9 \%$ students were in borderline level of this problem. About $27.4 \%$ students were facing total difficulties problems and $38.1 \%$ students were in borderline level. In terms of above all mental health status, boys were found to have more problems than girls. But no significant differences were found between boys and girls at any dimension score or even total difficulties score.
\end{abstract}

Key words: Mental health, conduct problem, peer problem, pro-social problem, emotional problem.

\section{INTRODUCTION}

Mental health means the overall mental condition of a person. It is the overall condition of a person's personality, intelligence, memory, emotion, sensation, perception, learning process, adjustment pattern, problem solving behavior, etc. When a person is free from anxiety, stress, emotional disturbance, mental illnesses, etc. and can interact properly with others and his own works. We can say that the person is maintaining excellent mental health.(Ali 1998)

*Corresponding author:arunavocu@ yahoo.com 
Children, specially boys and girls are facing a lot of hazards in this stage of their life. Parents named this stage as troublesome age; teachers labeled this stage as elementary school and psychologist called this stage as the gang age (Hurlock 2000).

The cause of mental health problems are lack of self-control, emotional turmoil, and negative thinking (Santrock 2005). Sometimes school environments lead to mental disorder or stress among the children. Mature students are mostly well- adjusted to the school situation. In general, they have many peers or sharing groups with whom they can share their daily problems and activities and release themselves. But, the primary school children are more sensitive and facing more problems as they generally used to the social environment. Different children come from different family background. When children get admitted into primary school, suddenly they find themselves in a broader and unknown environment. They face problems to cope with their school discipline. The well mentally functioned students easily can overcome the hardness. But, those who do not have balanced mental health suffer internally. Then Mental Health becomes associated with increased exposure to health risk factors, poorer physical health.

According to $\mathrm{WHO}$, about 8.4 million people in Bangladesh are suffering from mental health problem. This is about $7 \%$ of the population of 120 million (Banglapedia 2006). Around one-fourth of children are suffering from some forms of mental health problem (Rabbani et al. 2009). Another research found that about 9.5 to $29 \%$ of children in most of the countries are suffering from various mental health problems (The Daily Star, 15 June, 2011). 16.1\% of Bangladesh's adult population are suffering from some forms of metal health disorder (Firoz et al. 2007).

The survey, conducted with financial assistance of WHO in Bangladesh, says children growing up in rural areas are more prone to mental health problems than their urban counterparts. Lower level of education of parents, history of mental illness in the family and past head injuries have been identified as the reasons behind the mental health problems. The research also found that about 17.5 percent of the children suffering from mental health problems are from rural areas while14.3 percent from cities (The Daily Star, 15 June, 2011).

Childhood mental illness occurs in about $20 \%$ of U.S. children in a year, according to the U.S. Surgeon General. Further, nearly 5 million U.S. children 
MENTAL HEALTH STATUS OF PRIMARY SCHOOL CHILDREN OF CHITTAGONG TOWN

have some type of serious mental illness (one that significantly interferes with daily life). (Chakraburtty 2009)

Children mental health problems can interrupt daily life at home, at school or in the society. It can lead to academic failure, alcohol or other drug abuse, family conflict, violence or even suicide. Some of the mental disorders commonly seen in children are depression, conduct disorder, hyperactivity, aggressiveness, delinquency, schizoid anxiousness, social withdrawal, nervousness, inattentiveness, self-destructiveness, sex problems etc. (Banglapedia 2006)

As many as one in ten children between ages six and twelve experience continual feelings of sadness is the sign of depression. Parents should be aware of some key behaviors that may be signal of depression in children are- sudden drop in school performance, loss of interest or pleasure in activities once enjoyed, Outbursts of shouting, complaining, unexplained irritability, or crying, thoughts of death or suicide, expressions of fear or anxiety, aggression, refusal to cooperate, antisocial behavior, use of alcohol or other drugs, constant complaints of aching arms, legs, or stomach with no apparent cause etc. (APA 2011).

The main features of Attention-Deficit Hyperactivity Disorder (ADHD) include hyperactivity, impulsiveness, and an inability to sustain attention or concentration. These symptoms occur at levels that cause significant distress and impairment and are far more severe than typically found in children of similar ages and developmental levels. More common in boys than in girls, this disorder often develops before age seven, but is usually diagnosed between ages 8 and 10 . Children with ADHD have difficulty finishing any activity that requires concentration, don't seem to listen to anything said to them, are excessively active running or climbing at inappropriate times, squirming in or jumping out of their seats, are very easily distracted, talk incessantly, often blurting out responses before questions are finished, have serious difficulty waiting their turn in games or groups, may have specific learning disabilities (APA 2011).

Children with conduct disorder show a continual disregard for the norms and rules of society. Conduct disorder is very common mental disorders in adolescents. The symptoms are closely tied to socially unacceptable or violent behavior. Many people confuse this illness with either juvenile delinquency or the turmoil of the teen years. Children who have demonstrated at least three of the 
following behaviors over six months should be evaluated for possible conduct disorder are- stealing, constantly lying, deliberately setting fires, skipping school, breaking into homes or offices, deliberately destroying others' property, displaying physical cruelty to animals or humans, forcing others into sexual activity, often starting fights, using weapons in fights etc (APA 2011).

Children with emotional problems in primary school are unable to learn because they cannot pay attention, remember information on purpose, or act properly in a school environment. As a result it is hard to manage them in the classroom. These children cannot get along with each other, follow directions, and are impulsive. They show hostility and aggression in the classroom or on the playground (http://www.brighttots.com/ Emotional_disorder 2011).

Prosocial behavior, or "voluntary behavior intended to benefit another", (Eisenberg 2007) consists of actions which "benefit other people or society as a whole," (PsychWiki 2011) "such as helping, sharing, donating, co-operating, and volunteering." Prosocial behavior fosters positive traits that are beneficial for children and society. It may be motivated both by altruism and by self-interest, for reasons of immediate benefit or future reciprocity. "Prosocial behavior" is associated with developing desirable traits in children.

The feelings of satisfaction and security that most of the children derive from interacting with peers outweigh periodic problems. For a number of children, however, peer relations are persistently problematic. Some children are actively rejected by peers. Others are simply ignored, or neglected. It even appears that some popular children have many friends but nevertheless feel alone and unhappy.

Children who are unable to form close or satisfying relationships with peers should be of concern both to parents and teachers. For one thing, these children do not get enough opportunities to learn social skills that will be important throughout their lives. Especially critical are the skills needed to initiate and maintain social relationships and to resolve social conflicts, including communication, compromise, and tact (Asher et al. 1982). Children who lack ongoing peer involvements also may miss opportunities to build a sense of social self-confidence. 
MENTAL HEALTH STATUS OF PRIMARY SCHOOL CHILDREN OF CHITTAGONG TOWN

These children may develop little faith in their own abilities to achieve interpersonal goals thus; they are easily overwhelmed by the normal ups and downs of social interaction. Implications for the children's future social and professional adjustments are obvious.

Finally, children without satisfying friendships may suffer from painful feelings of isolation (Asher et al. 1984). School may be an unpleasant place for the children. They may ultimately become truant or drop out altogether (Kupersmidt 1983). Or, in their search for a sense of group belonging, the children may become vulnerable to the influence of delinquent or drug-abusing peers (Isaacs 1985).

Some of these disorders, such as anxiety disorders, eating disorders, mood disorders and schizophrenia, can occur in adults as well as children. Others begin in childhood only, although they can continue into adulthood. It is not unusual for a child to have more than one disorder. These can hamper the primary school life of children.

Kessler et al. (2005) found in their research that approximately half of adult mental health disorders have an onset before the age of 14 (Kessler et al. 2005. Kim-Cohen et al. 2003).

Patel et al. (2007) found in their research that poor mental health in young people is associated with a host of other difficulties including poor educational attainment, substance misuse, violence, and poor reproductive and sexual health (Patel et al. 2007).

Fleitlich and Goodman (2001) carried out a cross sectional survey of school children between the ages of 7-14 years in three contrasting neighborhoods in a Brazilian district, a shanty town, a stable urban neighborhood, and a rural village and found significant associations of child mental health problems with poverty as well as with maternal mental illness and witnessing family violence.

Grantham-Mcgregor et al. (2007) in their study carried out in rural Bangladesh highlighted the association of malnutrition with particular temperamental and behavioral characteristics. It is found that malnutrition impacts on children's development, including motor, language, and cognitive development. 
Patel et al. (2008) explore the links between The Millennium Development Goals and child and adolescent mental health. They highlight how childhood emotional and learning disorders contribute to school dropout, as shown by studies from South Africa, India, and Brazil. Ensuring universal primary education is a key MDG as it gives children the chance to build a better life for themselves and combat the intergenerational cycle of poverty. A number of primary prevention programs have been successfully implemented in high-income countries (Flament et al. 2007).

Rabbani et al. (2009) in his research showed $2 \%$ of the surveyed population is suffering from epilepsy, $3.8 \%$ from intellectual disability, $0.8 \%$ from drug addiction and $18.4 \%$ from various forms of mental health problems. The report also highlights a lack of awareness about mental health problems in the country, we may say it make a child unproductive and burden to their family.

Study on behavioural problems in children in Dhaka, Bangladesh revealed that mothers reported $11.8 \%$ of boys and $10.7 \%$ of girls, and teachers reported $12.8 \%$ of boys and $11.2 \%$ of girls to have behaviour problem in the clinical range. Boys scored significantly higher than girls, and children from lower socioeconomic status obtained higher problem score than children from upper and middle socio-economic status (Banglapedia 2006).

Childhood had a great influence on a person. So, it is our duty as a researcher to make people aware of and concerned to person's childhood life healthy both physically and mentally to build a good healthy nation. We have great concern about our children's physical health but we ignore their mental health totally. But there is also a great impact of mental health on personality from childhood life. Specially school going children suffer from various mental problems. In the developed country, the government pays special attention to the children's mental health care understanding its importance. But in our country this term 'mental health' is not so concerning a matter, even there is no statistics to the government about children's mental health. Only some national or international organizations are working in this area. WHO identifies that 8.4 million people of Bangladesh is suffering from mental health problem and 9.5 to $29 \%$ of them are children (Banglapedia 2006). But these studies are not enough to explore the children's mental health status of Bangladesh. We need more research on children's mental health and this study will also help to explore some state of mental health condition of children. Mental health promotion and prevention of mental disorders are interlinked as the former builds resilience and hence reduces risk of 
MENTAL HEALTH STATUS OF PRIMARY SCHOOL CHILDREN OF CHITTAGONG TOWN

developing disorder. Mental health is an essential component in enabling individuals to fulfill their potential. The Millennium Development Goals (MDG) does not address mental health directly, but addressing child and adolescent mental health needs can assist in achieving them. In Bangladesh, when people speak of health, they generally consider the physical health. In this country, the Ministry of Health and Family Planning has undertaken many health care projects which are monitored by the Director General of Health, the key person, who is always a medical doctor and the major emphasis is always on physical health. Lesser importance is given on the matters related to mental health and social health not only by the Government, but by all concerned. But health is best understood in terms of a combination of biological (physical), psychological (mental) and social factors (Stowell 2003). So, this study helps them to understand, be aware of and give great importance on the mental health.

The objective of the study was to explore the mental health condition specially the severity level of strength and difficulties of the primary school going children of Chittagong town.

\section{MATERIALS AND METHODS}

\section{Sample}

The sample of the present study constituted of 197 parents of primary school children. Among the 197 parents, 129 parents had boys and 68 parents had girls. The samples of both groups were purposively selected from various primary schools in Chittagong Town. The ages of their children were in between 5-13. These children belong to different age-groups, socio-economic status and educational background.

\section{Measuring Instrument}

To measure the mental health status, Strengths and Difficulties Questionnaire (SDQ) for parents was used. It is originally developed by R. Goodman (1997) and Bangla version is translated by Mullick and Goodman (2001). The SDQ contains 25 items, divided into 5 dimensions, such as Conduct problem (five items), Emotional Problem (five items), Hyperactivity (five items), Peer problems (five items), Pro-social behavior (five items). Each item was followed by 3 alternatives: not true, somewhat true and certainly true. Certainly true is given 2 points, somewhat true 1 point and not true 0 points. The range of test-retest value is from 0.70 to 0.85 and internal consistency ranges from 0.51 to 0.76 . 


\section{Design}

Cross sectional survey design was used.

\section{Procedure}

For the present study, the main purpose was to collect information about the mental health condition of primary school children. For this reason, sample was selected purposively from different primary schools of Chittagong town. After taking permission of primary school authority and with the help of the class teacher, 129 boys and 68 girls were selected. Each child was given a "Strength and Difficulties Questionnaire" (SDQ) in a sealed envelope to take to their mother (instruction was given in each questionnaire). Mothers were requested to return the filled up questionnaire in a sealed envelope to the class teacher. I collected the envelopes from the class teacher. To administrate the SDQ questionnaire per individual respondent required 15 to 25 minutes approximately. All data were collected within 20 days. At completion of the questionnaire thanks were given to the authority of the primary school. In this study, Strength and Difficulties Questionnaire was administrated by a standard procedure.

\section{RESULTS AND DISCUSSION}

The main objective of the study was to investigate the mental health condition of the primary school children of Chittagong town. Frequency distribution and $t$ test were used for analyzing data. These results are presented on the table 1. 
MENTAL HEALTH STATUS OF PRIMARY SCHOOL CHILDREN OF CHITTAGONG TOWN

TABLE 1: SEX WISE MENTAL HEALTH STATUS OF PRIMARY SCHOOLS CHILDREN OF CHITTAGONG TOWN.

\begin{tabular}{|c|c|c|c|c|c|c|c|c|c|c|c|c|c|}
\hline \multirow{3}{*}{ Problems } & \multirow{3}{*}{ Sex } & \multicolumn{6}{|c|}{ Mental Health Status } & & & \multirow{3}{*}{$\mathbf{M}$} & \multirow{3}{*}{ SD } & \multirow{3}{*}{ df } & \multirow{3}{*}{$\mathbf{t}$} \\
\hline & & \multicolumn{2}{|c|}{ Abnormal } & \multicolumn{2}{|c|}{ Borderline } & \multicolumn{2}{|c|}{$\underline{\text { Normal }}$} & \multicolumn{2}{|c|}{$\underline{\text { Total }}$} & & & & \\
\hline & & $\mathbf{N}$ & $\%$ & $\bar{N}$ & $\%$ & $\mathbf{N}$ & $\%$ & $\mathbf{N}$ & $\%$ & & & & \\
\hline \multirow[t]{3}{*}{ Pro-social behavior } & Boy & 26 & 65.0 & 23 & 60.5 & 80 & 67.2 & 129 & 65.5 & 6.14 & 1.70 & \multirow{2}{*}{195} & \multirow{2}{*}{0.54} \\
\hline & Girl & 14 & 35.0 & 15 & 39.5 & 39 & 32.8 & 68 & 34.5 & 6.00 & 1.74 & & \\
\hline & Total & 40 & 100.0 & 38 & 100.0 & 119 & 100.0 & 197 & 100.0 & & & & \\
\hline \multirow[t]{3}{*}{ Peer Problem } & Boy & 0 & 0.0 & 25 & 80.6 & 104 & 63.0 & 129 & 65.5 & 2.58 & 0.95 & \multirow{2}{*}{195} & \multirow{2}{*}{-0.57} \\
\hline & Girl & 1 & 100.0 & 6 & 19.4 & 61 & 37.0 & 68 & 34.5 & 2.66 & 0.92 & & \\
\hline & Total & 1 & 100.0 & 31 & 100.0 & 165 & 100.0 & 197 & 100.0 & & & & \\
\hline \multirow[t]{2}{*}{ Hyperactive } & Boy & 10 & 76.9 & 7 & 63.6 & 112 & 64.7 & 129 & 65.5 & 4.36 & 1.60 & \multirow{2}{*}{195} & \multirow{2}{*}{1.58} \\
\hline & Girl & 3 & 23.1 & 4 & 36.4 & 61 & 35.3 & 68 & 34.5 & 4.00 & 1.41 & & \\
\hline \multirow{4}{*}{ Emotional symptom } & Total & 13 & 100.0 & 11 & 100.0 & 173 & 100.0 & 197 & 100.0 & & & \multirow{4}{*}{195} & \multirow{4}{*}{1.82} \\
\hline & Boy & 2 & 66.7 & 1 & 100.0 & 126 & 65.3 & 129 & 65.5 & 2.23 & 1.96 & & \\
\hline & Girl & 1 & 33.3 & 0 & 0.0 & 67 & 34.7 & 68 & 34.5 & 1.72 & 1.70 & & \\
\hline & Total & 3 & 100.0 & 1 & 100.0 & 193 & 100.0 & 197 & 100.0 & & & & \\
\hline \multirow{2}{*}{ Conduct Problem } & Boy & 30 & 78.9 & 26 & 55.3 & 73 & 65.2 & 129 & 65.5 & 3.20 & 1.94 & \multirow{2}{*}{195} & \multirow{2}{*}{1.00} \\
\hline & Girl & 8 & 21.1 & 21 & 44.7 & 39 & 34.8 & 68 & 34.5 & 2.94 & 1.54 & & \\
\hline \multirow{4}{*}{ Total difficulties } & Total & 38 & 100.0 & 47 & 100.0 & 112 & 100.0 & 197 & 100.0 & & & \multirow{4}{*}{195} & \multirow{4}{*}{2.03} \\
\hline & Boy & 44 & 81.5 & 46 & 61.3 & 39 & 57.4 & 129 & 65.5 & 18.57 & 4.45 & & \\
\hline & Girl & 10 & 18.5 & 29 & 38.7 & 29 & 42.6 & 68 & 34.5 & 17.28 & 3.74 & & \\
\hline & Total & 54 & 100.0 & 75 & 100.0 & 68 & 100.0 & 197 & 100.0 & & & & \\
\hline
\end{tabular}

Table 1 showed that different mental health condition of primary school children with their three severity levels sex wise. At first in pro-social behavior problem, it was found that out of 197 respondents 40 respondents were abnormal, among them $65.0 \%$ were boys and $35.0 \%$ were girls. On the other hand out of 197 respondents 38 respondents were found borderline levels, among them $60.5 \%$ were boys and $39.5 \%$ were girls. Rest of 119 out of 197 had no problem in prosocial behavior problem. Total boys $(\mathrm{N}=129, \mathrm{M}=6.14, \mathrm{SD}=1.70)$ and girls $(\mathrm{N}=68$, $\mathrm{M}=6.00, \mathrm{SD}=1.74) \mathrm{t}$ score was 0.54 in this pro-social behavior problem.

In Peer problem, it was seen that out of 197 respondents 1 respondent was in abnormal level and 31 respondents out of 197 were in borderline level, among them $80.6 \%$ were boys and $19.4 \%$ were girls. Rest of 165 out of 197 had no problem in this peer problem behavior. Total boys $(\mathrm{N}=129, \mathrm{M}=2.58, \mathrm{SD}=0.95)$ and girls $(\mathrm{N}=68, \mathrm{M}=2.66, \mathrm{SD}=0.92) \mathrm{t}$ score was -0.57 in this Peer problem. 
In the Hyperactive problem, it was found that out of 197 respondents 13 respondents were in abnormal level, among them $76.9 \%$ were boys and $23.1 \%$ were girls. However, 11 respondents out of 197 were in borderline level, among them $80.6 \%$ were boys and $19.4 \%$ were girls. Rest of 173 out of 197 had no problem in this hyperactive problem. Total boys $(\mathrm{N}=129, \mathrm{M}=4.36, \mathrm{SD}=1.60)$ and girls $(\mathrm{N}=68, \mathrm{M}=4.00, \mathrm{SD}=1.41) \mathrm{t}$ score was 1.58 in this Hyperactive problem.

In the emotional symptom problem, it was found that out of 197 respondents 3 ( 2 boys, 1 girl) respondents were in abnormal level. In borderline level 1 respondent was found out of 197 respondents. Rest of 193 out of 197 had no problem in emotional symptom problem. Total boys $(\mathrm{N}=129, \mathrm{M}=2.23$, $\mathrm{SD}=1.96)$ and girls $(\mathrm{N}=68, \mathrm{M}=1.72, \mathrm{SD}=1.70) \mathrm{t}$ score was 1.82 in this emotional symptom problem.

In the conduct problem, it was found that out of 197 respondents 38 respondent were in abnormal level, among them $78.9 \%$ were boys and $21.1 \%$ were girls. On the other hand 47 respondents out of 197 were in borderline level, among them 55.3\% were boys and 44.7\% were girls. Rest of 112 out of 197 respondents had no problem. Total boys $(\mathrm{N}=129, \mathrm{M}=3.20, \mathrm{SD}=1.94)$ and girls $(\mathrm{N}=68, \mathrm{M}=2.94, \mathrm{SD}=1.54) \mathrm{t}$ score was 1.00 in this conduct problem behavior.

In Total difficulties problem, it was shown that out of 197 respondents 54 respondents were in abnormal level, among them $81.5 \%$ were boys and $18.5 \%$ were girls. However, 75 respondents out of 197 were found in borderline level, among them $61.3 \%$ were boys and $38.7 \%$ were girls. Rest of 68 out of 197 respondents had no problem. Total boys $(\mathrm{N}=129, \mathrm{M}=18.57, \mathrm{SD}=4.45)$ and girls $(\mathrm{N}=68, \mathrm{M}=17.28, \mathrm{SD}=3.74) \mathrm{t}$ score was 2.03 in total difficulties status.

From table 1 we can see that $20.3 \%$ students have pro-social problem severely out of 197 students. They do not show co-operative, sharing, helping, volunteering behavior to other. However, $19.3 \%$ students were in the borderline level of pro-social behavior problem. These students are less problematic than that of abnormal level students. It is also found that boys are more problematic in number than girls in both abnormal and borderline levels. But there were no significant differences between boys and girls as their pro-social problem score.

It was seen that only 1 girl was in abnormal level in the case of Peer problem out 197 students. This child may suffer from painful feelings of isolation. School may be an unpleasant place for her. She may ultimately become truant or drop out altogether. That child may become vulnerable to the influence of delinquent or drug-abusing peers also. About $15.7 \%$ students were found at the borderline level 
MENTAL HEALTH STATUS OF PRIMARY SCHOOL CHILDREN OF CHITTAGONG TOWN

of this problem. They were found less problematic than abnormal level. Boys are found more in number than girls in this borderline level. But there were no significant differences between boys and girls as their Peer problem score.

It was found that $6.6 \%$ students were in abnormal level in the case of hyperactivity problem out of 197 students. These students are impulsive and unable to sustain attention to or concentration on any task properly. Sometimes they may show specific learning disability. About 5.6\% students were found at borderline level of this problem. They are found less problematic than abnormal level. In both levels boys are found more in number than girls. But there were no significant differences between boys and girls as their hyperactivity problem score.

It was seen that only $1.5 \%$ (66.7\% boys, $33.3 \%$ girls $)$ students were in abnormal level in the case of Emotional symptom problem out 197 students. These children may be unable to learn because they cannot pay attention, remember information on purpose, or act properly in a school environment. It is hard to manage these type students in the classroom. These children cannot get along with each other, follow directions, and are impulsive. They show hostility and aggression in the classroom or in the playground. Out of 197 students 1 boy was found at borderline level. He felt fewer problems than those of abnormal level students. But there were no significant differences between boys and girls as their Emotional symptom score.

In conduct problem behavior it was found that $19.3 \%$ students were in abnormal level out of 197 students. They may show a continual disregard for the norms and rules of society. Sometimes they express socially unacceptable or violent behavior. They may also be found at least three of the following six behaviors over six months-stealing, constantly lying, deliberately setting fires, skipping school, breaking into homes or offices, deliberately destroying others' property, displaying physical cruelty to animals or humans, forcing others into sexual activity, often starting fights, using weapons in fights. About 23.9\% students were in borderline level of this problem out of 197 students. These borderline level girls and boys were less problematic than those of abnormal level boys and girls. Boys were found more in number than girls in both abnormal and borderline levels. But there were no significant differences between boys and girls according to their conduct problem score. 
Finally, it was seen that about $27.4 \%$ of students were in abnormal level, out of 197 students in the case of Total difficulties problem. This was the combined information of mental health disorder. Boys were found more in difficulties than girls in total combined mental health disorder. It was also found that $38.1 \%$ of students were in borderline level, among them $61.3 \%$ were boys and $38.7 \%$ were girls. It showed that these students were in marginal line of mental disorder. Any time they can be affected in mental disorder. But there were no significant differences between boys and girls according to their Total Difficulties problem score.

All of the problems mentioned above, show that those who are at borderline levels as mental health status, are in marginal line. At any time they tend to become or take turn into abnormal level.

\section{Findings}

About $20.3 \%$ students had pro-social problem and about $19.3 \%$ students were in borderline level in pro-social behavior. Only $0.5 \%$ students had Peer problem and about $15.7 \%$ students were found at borderline level of this problem. About $6.6 \%$ students had hyperactivity problem and about $5.6 \%$ students were found at borderline level of this problem. About 1.5\% students had Emotional symptom problem and $0.5 \%$ students were found at borderline level. About $19.3 \%$ students had conduct problem and $23.9 \%$ students were in borderline level of this problem. About $27.4 \%$ students were facing total difficulties problems and $38.1 \%$ students were in borderline level. In all mental health status boys were found more in number than girls. But no significant differences between boys and girls were found at any problems.

\section{Recommendation}

We can recommend that an immediate treatment program should be arranged for those children who are in vulnerable position. Otherwise, we will find those affected students in the dropout list. We can introduce mental health problems into primary care services. Professionals in other sectors working with children (teachers, school counselors, social workers) should target in spreading successful interventions for child mental health problems. Mental health information aimed at school children can help to increase knowledge and understanding of mental health issues not only among the children themselves, but also in the families and neighbors. It was originated from an emergency program to address the mental health needs of children by Child Advocacy International and evolved into a community-based service. Or the authority can appoint psychologist or counselor who will take care and ensure mental health of those children of their institution. 
MENTAL HEALTH STATUS OF PRIMARY SCHOOL CHILDREN OF CHITTAGONG TOWN

That can reduce mental health problem and decreases dropout list of children. Finally, we expect the government to give proper concentration on this mental health issue and add this issue properly to the health policy of the country.

There are some limitations in the present study. Due to lack of financial support the whole areas could not been observed fully. Some parents of the students are illiterate and they did not participate in this study. Some parents are not conscious about their children's mental health and some parents have avoided to participate in the study. Further research will need more specific problem identification in this issue.

\section{REFERENCES}

ALI, MUDASSER. 1998. Mental Health of the Child Labours of Bagha Upazilla, Unpublished thesis, Rajshahi University, 3 pp.

APA, 2011. American Psychiatric Association, Children's Mental Health http://healthyminds.org/More-Info-For/Children.aspx.

ASHER, S. R., RENSHAW, P.D. AND HYMEL, S. 1982. "Peer Relations and the Development of Social Skills." In the young child: Reviews of Research. 3:169-171, edited by Moore, S.G. and Cooper, C. R. Washington, D.C.: National Association for the Education of Young Children.

ASHER, S.R., HYMEL, S. AND RENSHAW, P.D. 1984. "Loneliness in Children." Child Development 55 :1456-1464.

BANGLAPEDIA, 2006. The National Encyclopedia of Bangladesh, Mental Illness, Asiatic Society of Bangladesh, Nimtali, Dhaka.

CHAKRABURTTY, A.M.A.L. 2009. Mental Illness in Children, Web MD Medical, LLC, http://www.webmd.com/mental-health/mental-illnesschildren.

EISENBERG, H. 2007. "Prosocial Development". Handbook of Child Psychology. Jhon Wiley \& Sons,Inc. New Jersey, ISBN 0470147652. 646 pp.

FIROZ A.H.M., KARIM M.E., ALAM M.F., RAHMAN M. AND ZAMAN M.M, 2007. Community based multi-centre service oriented research on mental illness with focus on awareness, prevalence, care, acceptance and follow-up in Bangladesh 2003-2005. National Institute of Mental Health, Dhaka. Bangladesh J. Psychiatry ; 20(1): 9-32. 
FLAMENT, M.F., NGUYEN, H., FURINO, C., SCHACHTER, H., MACLEAN, C., AND WASSRMAN, D. 2007. Evidence based primary prevention programmes for promotion of mental health in children and adolescents. A Systematic Worldwide Review. In Remschmidt, H., Nurcombe, B., Belfer, M., Sartorius, N and Okasha, A. (2005), The mental health of adolescents: An area of global neglect Chichester, UK: Wiley. pp. 65-66.

FLEITLICH, B. AND GOODMAN, R. 2001. Social factors associated with child mental health problems in Brazil: Cross sectional survey. British Medical Journal, 323: 599-600.

GOODMAN, R. 1997. The Strengths and Difficulties Questionnaire: A research note. Journal of Child Psychology and Psychiatry. 38: 581-586.

GRANTHAM-MCGREGOR, S., CHEUNG, Y., CUETO, S., GLEWWE, P., RICHTER, L. AND STRUPP, B. 2007. Child development in developing countries: Developmental potential in the first 5 years for children in developing countries. The Lancet, 369: 60-70.

HURLOCK, E.B. 2000. "Developmental Psychology: A Life-Span Approach”, Tata MacGraw-Hill. New York. pp. 165-166.

ISAACS, S. 1985 "Popularity", Parents' Magazine, August :58-62.

KESSLER, R. C., BERGLUND, P., DEMLER, O., JIN, R. AND WALTERS, E. E. 2005. Lifetime prevalence and age-of-onset distributions of DSM-IV disorders in the National Comorbidity Survey Replication. Archives of General Psychiatry, 62: 593-602.

KIM-COHEN, J., CASPI, A., MOFFITT, T. E., HARRINGTON, H., MILNE, B. J. AND POULTON, P. J. 2003. Prior juvenile diagnoses in adults: Developmental follow back of a prospective longitudinal cohort. Archives of General Psychiatry, 60: 709-717.

KUPERSMIDT, J. B. 1983. "Predicting Delinquency and Academic Problems from Childhood Peer Status." Paper presented at the biennial meeting of the Society for Research in Child Development, Detroit, Michigan, April 21-24.

MULLICK, M.S.I. AND GOODMAN, R. 2001. Questionnaire screening for mental health problems in Bangladeshi children: a preliminary study. Social Psychiatry and Psychiatric Epidemiology, 36(2) : 94-99.

PATEL, V., FLISHER, A. J., HETRICK, S. AND MCGORRY, P. 2007. Mental health of young people: A global public-health challenge. The Lancet, 369: 1302-1313. 
MENTAL HEALTH STATUS OF PRIMARY SCHOOL CHILDREN OF CHITTAGONG TOWN

PATEL,V., FLISHER, A.J., NIKAPOTA AND MALHOTRA. 2008. Promoting child and adolescent mental health in low and middle income countries. $J$. Child Psychological Psychiatry. 49(3): 313-334.

PSYCHWIKI. COM, 2011. Prosocial behavior, PsychWiki.com, Aug. 4.

RABBANI, M. G., ALAM, M. F. AND AHMED, H. U. 2009. Prevalence of Mental disorders, Mental retardation, Epilepsy and Substance abuse in Children: A community based epidemiological survey. Disseminated in a session of WPA regional conference, Dhaka, Bangladesh. pp.11-12.

SANTROCK, J. W. 2005. A Topical Approach to Life-Span Development of Health, McGraw-Hill Companies, Inc, 1221 Avenue of the Americas, New York, NY, 10020, 132 pp.

STOWELL, J. R., MCGUIRE, L., GLASER, R. AND KIECOLT-GLASER, J. 2003. Psychonuroimmunology in I. B.Weiner(Ed), Handbook of Psychology (Vol. IX). New York: Wiley. 191 pp.

THE DAILY STAR, 2011. One in four children faces mental disorder: Study, Wednesday, June 15, 2011.

Manuscript received on 12.01.2012; Accepted on 07.07.2012

The Chittagong University Journal of Biological Sciences, Vol. $6(1$ \& 2). Page No. 